\title{
The experience of women in male-dominated occupations: A constructivist grounded theory inquiry
}

\begin{tabular}{|c|c|}
\hline \multicolumn{2}{|c|}{$\begin{array}{l}\text { Authors: } \\
\text { Phiona Martin }{ }^{1} \\
\text { Antoni Barnard }{ }^{1}\end{array}$} \\
\hline \multicolumn{2}{|c|}{$\begin{array}{l}\text { Affiliations: } \\
{ }^{1} \text { Department of Industrial } \\
\text { and Organisational } \\
\text { Psychology, University of } \\
\text { South Africa, South Africa }\end{array}$} \\
\hline \multicolumn{2}{|c|}{$\begin{array}{l}\text { Correspondence to: } \\
\text { Antoni Barnard }\end{array}$} \\
\hline \multicolumn{2}{|c|}{$\begin{array}{l}\text { Email: } \\
\text { barnaha@unisa.ac.za }\end{array}$} \\
\hline \multicolumn{2}{|c|}{$\begin{array}{l}\text { Postal address: } \\
\text { PO Box 392, Universit } \\
\text { South Africa 0003, } \\
\text { South Africa }\end{array}$} \\
\hline \multicolumn{2}{|c|}{$\begin{array}{l}\text { Dates: } \\
\text { Received: } 25 \text { Feb. } 2013 \\
\text { Accepted: } 20 \text { May } 2013 \\
\text { Published: } 28 \text { June } 2013\end{array}$} \\
\hline \multicolumn{2}{|c|}{$\begin{array}{l}\text { How to cite this article: } \\
\text { Martin, P., \& Barnard, A. } \\
\text { (2013). The experience of } \\
\text { women in male-dominated } \\
\text { occupations: A constructivist } \\
\text { grounded theory inquiry. } \\
\text { SA Journal of Industrial } \\
\text { Psychology/SA Tydskrif vir } \\
\text { Bedryfsielkunde, 39(2), Art. } \\
\text { \#1099, } 12 \text { pages. http:// } \\
\text { dx.doi.org/10.4102/sajip. } \\
\text { v39i2.1099 }\end{array}$} \\
\hline \multicolumn{2}{|c|}{$\begin{array}{l}\text { Copyright: } \\
\text { (C) 2013. The Authors. } \\
\text { Licensee: AOSIS } \\
\text { OpenJournals. This work } \\
\text { is licensed under the } \\
\text { Creative Commons } \\
\text { Attribution License. }\end{array}$} \\
\hline \multicolumn{2}{|l|}{ Read online: } \\
\hline 口ifing & $\begin{array}{l}\text { Scan this QR } \\
\text { code with your } \\
\text { smart phone or } \\
\text { mobile device } \\
\text { to read online. }\end{array}$ \\
\hline
\end{tabular}

Orientation: Women in male-dominated occupations face unique challenges and use distinct coping strategies affecting their motivation and retention in these occupations.

Research purpose: The purpose was to explore the experiences of women working in maledominated occupations to clarify the challenges they face and identify coping strategies that enable them to continue on their career paths.

Motivation for the study: Many women who choose male-dominated careers soon change in favour of more female-dominated or gender-balanced career paths. An understanding of women's experiences may facilitate strategies geared towards their motivation and retention in male-dominated occupations.

Research design, approach and method: The authors conducted this exploratory qualitative study from a constructivist grounded theory perspective. They used a purposive sample of five women and conducted in-depth unstructured interviews. They analysed data using a constructivist grounded theory methodology.

Main findings: The authors found that formal and covert organisational practices, which upheld gender discrimination and bias, were the main challenges that women face. These practices included the inadequate accommodation of women's unique physical, identity and work-life balance needs. Elements of women's resilience included the use of femininity, adopting male characteristics, mentorship and intrinsic motivational factors.

Practical/managerial implications: The findings may guide organisations to develop and implement policies, strategies and initiatives geared towards attracting, integrating, retaining, supporting and motivating women who are, or wish to be, employed in historically maledominated occupations.

Contribution/value-add: This study contributes to an evolving body of knowledge aimed at understanding how to integrate and retain women in male-dominated occupations better.

\section{Introduction}

Women who work in male-dominated occupations face challenges that differ from those who work in more gender-balanced and female-dominated occupations. These challenges affect their retention and career success. In this study, the authors explored the challenges these women face as well as how they cope and persevere despite them.

\section{Background to the study}

The South African female labour force has been growing because of equity legislation and improved access to education and work opportunities (Finnemore \& Cunningham, 1995; Franks, Schurink \& Fourie, 2006; Mostert, 2009; Van den Berg \& Van Zyl, 2008). However, progress with gender transformation and equity in the South African workplace is still unsatisfactory (Anonymous, 2012; Du Plessis \& Barkhuizen, 2012; Hicks, 2012; Lewis-Enright, Crafford \& Crous, 2009). There are powerful economic incentives for women to move into historically male-dominated occupations (England, 2010). Yet women who defy conventional female career patterns and choose to pursue careers in male-dominated occupations often return to careers that accommodate their roles as primary caregivers better (Ashraf, 2007; Cha, 2013; Danziger \& Eden, 2007; Frome, Alfeld, Eccles \& Barber, 2006).

The challenges women face in attempting to penetrate successfully and persevere in historically male-dominated work environments emanate from traditional gender hierarchies and norms that prevail in the family and society. Despite gender equality and empowerment, the household unit has a traditional structure - and still has - that makes males the dominant gender (Hartmann, 2010). These traditional stereotyped role expectations spill over to organisational policies and 
practices to maintain women's marginalised work roles (Bobbitt-Zeher, 2011; Cha, 2013) and become entrenched in a gender-biased organisational culture (Prescott \& Bogg, 2011).

Historically, men have dominated policy development (Taylor, 1997). Organisations are still structured and function in ways that do not always support women's career patterns and their need to integrate work with family responsibilities (Cha, 2013; Frome et al., 2006). Hicks (2012) refers to the invisible aspects of the male-dominated institutional culture that give lip service to gender empowerment strategies but continue to marginalise women. According to Finnemore and Cunningham (2005), men have predominantly recorded the history of women and work through their eyes.

Raghuram (2008) urges researchers to think in a different way about the effect of gender on career trajectories and aspirations in male-dominated environments. A focus on women in male-dominated occupations remains especially important in the light of studies that point to the negative personal and social consequences women face. Mostert (2009) highlights the effect of work-family conflict, as well as the demands of work and home on women's health whilst Mathur-Helm (2006) cautions against the consequent family relationship problems.

Further, women experience the world of work quite differently to how men do (Bobbitt-Zeher, 2011; Prescott \& Bogg, 2011). Generally, a desire for status, power and social comparisons drives men. On the other hand, a desire to do a good job and contribute to organisational functioning motivates women (Davey, 2008; Prescott \& Bogg, 2011). Women's unique work experiences, coupled with archaic work-life role structures based on gender (Hartmann, 2010), pose unique challenges to career-orientated women in general and, more specifically, to women who choose a traditionally male-dominated career.

The authors believe that organisations need to legitimise women's characteristics, natural behaviours and values and give them a platform in order to level the playing field for both genders.

\section{Research purpose}

According to Raghuram (2008), researchers have neglected to study women's experiences when they enter maledominated occupations. Retaining women in maledominated occupations remains a challenge because they tend not to stay in these occupations for long (cf. Du Plessis \& Barkhuizen, 2012; Mathur-Helm, 2006). Most studies focus on women in context-specific male-dominated occupations like engineering, banking, entrepreneurship and quantity surveying (Bowen, Cattell \& Distiller, 2008; Du Plessis \& Barkhuizen, 2012; Mathur-Helm, 2010; Urban, 2010), with a predominantly quantitative focus. Franks, Schurink and Fourie (2007) conducted a qualitative inquiry into the life-role construction of career-orientated women and emphasised specifically the need for more in-depth qualitative work on woman's experiences of their work-life roles. A qualitative approach to the experiences of women, who work specifically in historically male-dominated occupations, may contribute to our understanding of how women persevere and maintain their career motivation despite the challenges they experience.

With this study, the authors aimed to explore the experiences of women who work in male-dominated occupations to develop an understanding of the unique challenges they face and to discover the strategies they use to remain motivated and persevere in these environments.

\section{Contribution of the study}

Organisations that are trying to promote women's entry into, and success in, historically male-dominated occupations require information on the dynamics and consequences of increasing the numbers of female employees in these environments. The authors hope that findings from this study will provide organisations with important information for developing workable strategies and gender policies designed to ensure the success and sustainability of the coexistence of the two genders in previously male-dominated spheres, without dominance or discrimination.

From a research perspective, most South African researchers focus on quantitative studies of specific phenomena of women in specific male-dominated environments. The authors envisage that this study will contribute to the body of knowledge by adding a qualitative research perspective to the experiences of women who work in male-dominated occupations.

In the rest of this article, the authors present a literature review and then the design they followed, with specific reference to their research approach, strategy and methods. Lastly, they discuss their findings and conclude with recommendations for practice and research.

\section{Literature review}

South African research on gender issues at work from a woman's perspective have studied specific pre-defined phenomena like:

- The work-home interaction of working females (Brink \& De la Rey, 2001; Mostert, 2009; Van Aarde \& Mostert, 2008).

- The life-role construction of career-orientated women (Franks et al., 2006).

- Cross-cultural comparisons of stress in high-level career women (Van Den Berg \& Van Zyl, 2008).

- Women and affirmative action (Mathur-Helm, 2005).

- The challenges that woman principals in South Africa face (Moorosi, 2007).

- Gender differences in perceptions of workplace progression (Llyod \& Mey, 2007).

- The career barriers of women engineers (Du Plessis \& Barkhuizen, 2012).

- Women's entrepreneurial self-efficacy (Urban, 2010). 
- Issues of gender and race for South African quantity surveyors in the workplace (Bowen, Cattell \& Distiller, 2008).

Du Plessis and Barkhuizen (2012) focused their inquiry on the career path barriers that women engineers experience. Their findings echo international research in that they identified inadequate training and mentorship opportunities as the primary professional barriers to integrating women in the field of engineering. The authors also conclude that the most significant psychological barrier is gender discrimination. Similarly, Damaske (2011) found that negative psychological experiences, like gender stereotyping and discrimination in male occupations, caused women's movement from maledominated to female-dominated occupations. Feelings of bias and under-utilisation amongst women in male-dominated occupations are common (cf. Feyerherm \& Vick, 2005).

Other psychological barriers that inhibit women from reaching their potential in male-dominated occupations relate to their own stereotypical gender role expectations. These include stereotypical questions about women's competence and gender-role ideologies that lead to them feeling inadequate and to having low self-efficacy and low self-confidence (Damaske, 2011; Lewis-Enright et al., 2009; Mathur-Helm, 2006; Shantz \& Wright, 2011). Researchers have noted that salary inequities (or the female-male pay gap) exemplify gender inequality and discrimination and inhibit women's career progression (Ashraf, 2007; Feyerherm \& Vick, 2005; Hicks, 2012). As a result, women feel that their organisations do not take them seriously, that they do not receive challenging opportunities and subsequently do not receive the pay or positions commensurate with their talents.

In male-dominated occupations, men have more resources and definitional power to enforce discriminatory practices, policies and ideologies (Damaske, 2011; Mathur-Helm, 2006). The persisting lack of visible and tangible strategies to empower women in organisations, (Hicks, 2012; Madikizela \& Haupt, 2009) may well be because of male-dominated and gender-biased management strategies (Mathur-Helm, 2005).

In the construction industry, for example, women reported a lack of available funding that targets improving the status and qualifications of female employees (Madikizela \& Haupt, 2009). Male-dominated work environments further maintain a male model of career progression (Mathur-Helm, 2006) where performance equates with working longer hours and with presenteeism (Cha, 2013; Lewis-Enright et al., 2009). In this context, presenteeism involves staying on the job longer than expected in order to impress managers (Harris \& Giuffre, 2010; Lewis-Enright et al., 2009) and constitutes covert marginalisation of many women with family obligations (Cha, 2013). Remaining the primary caregivers in the family, whilst simultaneously juggling their work demands, could lead to women experiencing role overload and time management problems (Franks et al., 2006; Danziger \& Eden, 2007), further taxing women's sense of work-life balance (Du Plessis \& Barkhuizen, 2012).
Another challenge to women who pursue success in maledominated occupations relates to characteristic maletype behaviour expectations distinct to these occupations. Davey (2008) found that female graduates regard success as masculine and political in a male-dominated field. Therefore, in order to be successful in male-dominated environments, women have to behave in ways that are unnatural to them (cf. Chovwen, 2007; Du Plessis \& Barkhuizen, 2012). They have to take on aggressive male characteristics and competitive interactional styles in their organisational contexts and, according to Akingbade (2010), this puts them at a disadvantage.

In Davey's (2008) study, typical masculine behaviour related to success in a male-dominated environment included political game playing, aggressiveness, backstabbing, point-scoring, overconfidence and 'stitching people up'. The mechanisms women use to cope in male-dominated environments include mentorship and adopting participatory leadership styles like being caring, fair and encouraging, which is more attuned to their natural feminine inclination (Chovwen, 2007). Contrary to this, female graduates adopted uncharacteristic masculine behaviour, like self-seeking and individualistic behaviour, to survive (Davey, 2008). Ironically, some opinions point to the detrimental effect of adopting characteristic male behaviour on women's feelings of authenticity and work identity (Du Plessis \& Barkhuizen, 2012). Therefore, women seem caught between resisting and accommodating masculine politics (Davey, 2008).

For women, the difficulty of penetrating historically maledominated occupations, coupled with the unwillingness to accommodate them in those occupations, makes the environments unattractive for enticing substantial numbers of women into these fields and retaining them there. Further, a lack of understanding of the challenges that women face and how they cope in these environments may add to the poor integration and advancement of women in historically male-dominated occupations.

Therefore, the main research objective was to explore the experiences of women in historically male-dominated occupations to ascertain the challenges they face and the strategies they use to remain in their chosen fields.

\section{Research design Research approach}

With a predominantly explorative purpose for this qualitative inquiry, the authors followed a constructivist grounded theory approach.

Constructivist grounded theory allows data collection, data analysis and theory to stand in reciprocal relationships with each other and follows an iterative process of constant comparison within and amongst data cases, theory and researcher field notes and memos (Charmaz, 2011; GordonFinlayson, 2010; Strauss \& Corbin, 1990). 
The authors' ontological perspective that subjective experience is real and socially constructed (cf. Terre Blanche \& Kelly, 1999) aligns with the notion of critical or subtle realism (cf. Snape \& Spencer, 2004) and befits a constructivist orientation. Further to this, the authors believe that one can only understand reality through empathic engagement with subjective experience.

Therefore, constructivist (cf. Crotty, 2005) and relativist epistemological notions (see Charmaz, 2011) directed the authors' methodological choices. Constructivist grounded theorists see meaning as mutually constructed between the researcher and the researched (Charmaz, 2011). Therefore, the authors do not claim any neutrality in their process of making meaning here, yet they have tried to use rigorous data analysis strategies and to report on these.

\section{Research strategy}

Five individual case studies, together with grounded theory data collection and analysis, was the authors' research strategy. Through concurrent collection and analysis of data, the authors constantly compared data excerpts within and between the five cases as well as with relevant theory to the point of theoretical saturation, when they found no new themes emerging. With theory development as a grounded theory directive, they developed a core theoretical understanding of the experiences of women in maledominated occupations.

\section{Research method}

\section{Sampling}

Theoretical sampling directed the purposeful selection (cf. Babbie \& Mouton, 2001) of four women who were working in historically male-dominated occupations for a minimum of one year. The authors added consequent follow-up interviews with the same four women. After their initial engagement with, and analysis of, the data, they approached an additional participant to confirm theoretical saturation.

Table 1 describes the research participants.

\section{Research setting}

Four participants worked in the private sector and one in the public sector. In assessing the suitability of an occupation as male-dominated, the authors considered historical and current patterns in terms of the prevalence of female entry and occupation in the respective participants' occupations. The authors found that the participants in this study represented occupations that have been confirmed as male-dominated in, for example, information technology (IT) (Raghuram, 2008), engineering and mining (Du Plessis \& Barkhuizen, 2012) and engineering education (Du Plessis \& Barkhuisen, 2012).

\section{Entrée and establishing researcher roles}

Four of the participants were referrals from the researchers' colleagues or friends. The authors approached one directly, based on a recommendation from a participant, via email without any intermediary being involved. The intermediaries gave the authors an entrée to the four research participants through personal introduction, either personally or via e-mail. Thereafter, the authors approached potential participants directly with a telephonic invitation to participate. The authors discussed the research purpose and ethical parameters - like freedom to withdraw and confidentiality - with each participant before the interview and asked them to sign an informed consent document if they volunteered to participate. The authors reiterated the issue of confidentiality with the participants before and during the interviews.

\section{Data collection methods}

Through in-depth unstructured interviews, the authors attempted to elicit experiences of working in a typical maledominated occupation. The authors invited participants to 'Tell me a little bit more about yourself and your current work.' As the discussion flowed from there, the authors used counselling skill conventions, like paraphrasing, probing and reflection, to develop the discussion in line with the research context and objective. Subsequently, from a theoretical sampling standpoint, the authors conducted follow up interviews to elaborate or confirm emerging themes and meanings.

\section{Recording of data}

The authors recorded the interviews digitally and substantiated them with field notes. One of the authors acted as transcriber to ensure in-depth immersion in the data and transcribed the interviews verbatim into Microsoft Excel ${ }^{\circledR}$.

\section{Data analysis}

Following Charmaz (2011), coding and memoing are the primary grounded theory analytical conventions that the authors applied. The authors conducted the initial analysis of the first interview transcription line-by-line with each data piece (line, sentence or paragraph), which they labelled according to its significance in relation to the authors' research objective (cf. Charmaz, 2011). This line-by-line analysis is typical of open coding in classical grounded theory (Strauss \& Corbin, 1990).

TABLE 1: Participant details.

\begin{tabular}{lllllll}
\hline Research participant & Profession & Industry & Race & Years with company & Marital status \\
\hline RP1 & IT project manager & IT & White & More than 10 & Widowed \\
RP2 & Chief Safety Officer & Mining & White & More than 10 & Single \\
RP3 & Electrical engineering & Engineering Education & Asian & Fewer than 2 & Married & Minor children \\
RP4 & Locomotive operator & Mining & Black & Fewer than 2 & Single & None \\
RP5 & Electrical engineer & Energy & Black & Fewer than 2 & Single & None \\
\hline
\end{tabular}

$\mathrm{RP}$, research participant; IT, information technology. 
From these initial codes, the authors identified recurring themes that they re-labelled and categorised following a colour-coding process. In original classical grounded theory texts, researchers usually refer to this code categorising as the axial coding phase (Glaser \& Strauss, 1967; GordonFinlayson, 2010). Here, the authors marked similar codes or categories of codes with the same colour. Their analysis of subsequent interviews followed the same process and their coding and categorisation became increasingly refined as they noticed recurring themes whilst they started to compare codes within each data set and across data sets.

During the analytical process, the authors constantly compared data sets with each other and with identified codes as well as with the memos they were writing of their interpretations of the meanings underlying the codes and themes.

The authors added new themes that emerged to the point of saturation, which became more and more noticeable as their analyses progressed through the fourth and fifth transcriptions. The progressive abstraction of the codes, which initially seemed different but started to make sense in relation to one another, also showed saturation. Logically, they also started to collapse and build on a conceptually broader theme. In this sense, what is originally referred to as selective or theoretical coding (see Glaser \& Strauss, 1967; Gordon-Finlayson, 2010; Strauss \& Corbin, 1990) influenced the authors in that they reconnected their categorised data and combined them into themes as they noticed causal and consequential relationships between the categories of data.

The authors continued to write memos of their understanding of the codes and evolving themes throughout their analysis. These continued to evolve conceptually and became very significant and useful whilst they recorded the findings. Although the authors tried to avoid applying extant theoretical concepts to the data (especially at the beginning of the analysis), they acknowledged that their existing and evolving theoretical, experiential and personal perspectives affected their interpretations.

Therefore, their preconceived notions and work with positive psychology constructs, like resilience, work identity and work-life balance, affected their understanding and interpretations in this study. Their analyses ultimately progressed into a conceptual framework that consisted of two main themes, with respective explanatory sub-categories underlying each theme.

The conceptual framework the authors propose here presents their construction of women's experiences of working in male-dominated occupations and relates to what Charmaz (2011) refers to as forming a core theoretical idea as the outcome of a constructivist grounded theory study.

\section{Strategies the authors used to ensure quality data}

The authors attempted to ensure the credibility of the study with purposeful selection and transparent description of information-rich participants. Furthermore, they endeavoured to remain congruent to the methodological and epistemological notions that underlie constructivist grounded theory research in their planning, data analysis and reporting of the study.

Therefore, theoretical sampling influenced the authors to do follow-up interviews and to add an additional participant to their inquiry. In lieu of constant comparison (GordonFinlayson, 2010), they repeatedly checked transcripts against live recordings, case data with the research objective, with each other and with emerging themes.

The authors base the trustworthiness and rigour of the study on their comprehensive description of the research methodology, along with thick descriptions of the data (cf. Cooney, 2011). They attempted to establish the confirmability of results by integrating the findings with relevant literature as well as through participant confirmation and peer review (cf. Charmaz, 2011).

The ethics committee of the College of Economic and Management Sciences at the University of South Africa gave the study ethical clearance.

\section{Reporting}

In the next section, the authors describe main themes and sub-themes in detail. The verbatim extracts from the data ground the findings in the data and the authors have allocated numbers to the research participants (RP1, RP2, $\mathrm{RP3}, \mathrm{RP} 4$ and RP5) to ensure anonymity.

The authors' discussion and proposed conceptual framework follow the findings. Consistent with a constructivist grounded theory approach, the authors only integrated relevant literature in the later stages of the data analysis (cf. Charmaz, 2011). Their discussion of the conceptual framework reflects this.

\section{Findings}

Consistent with the research objective the authors pursued, their grounded theory analysis led them to structure the data according to two theme clusters: "The unique challenges women face in male-dominated occupations' and 'Elements of their resilience'. Their organised theme clusters, subsequent primary themes and their sub-themes follow.

\section{Theme cluster: Unique challenges women face in male-dominated occupations}

1. Formal and covert organisational practices that maintain discrimination and bias:

- Inadequate resources, biased infrastructure and policies.

- Spill over of stereotypical gender roles and expectations that relate to women.

- Lack of real transformation because of male resistance and prejudices. 
2. Woman's unique physical, work identity and work-life balance needs:

- Physical and health related difficulties women experience.

- Negative work-identity perceptions.

- Work-life balance.

\section{Theme cluster: Elements of women's resilience in male-dominated occupations}

1. Coping strategies and resources:

- appreciation of feminine advantage

- adopting male characteristics

- mentorship.

2. Motivational aspects of the work:

- optimistic expectation of future career possibilities

- challenging work and work engagement

- recognition and success.

A description of the themes follows and gives the authors' understanding of the participants' experiences as women who work in male-dominated occupations.

\section{Unique challenges that women face in male- dominated occupations}

The unique challenges that emerged from the data were twofold. Firstly, the male-dominated environment seems to maintain the gender-segregated status quo formally and covertly. Secondly, the authors found that women have unique physical, work identity and work-life balance needs that challenge their ability to function easily in a maledominated environment.

\section{Formal and covert organisational practices that maintain discrimination and bias}

Inadequate resources, biased infrastructure and policies: None of the participants was aware of any pertinent policies or practices that aimed to improve their integration and accommodation in the workplace. Instead, the verbatim quotes in Box 1a below show that the existing infrastructures, resources and policies benefitted male employees mostly. Participants from the mining industry especially noted their struggle with inadequate basic facilities and resources. This resulted in personal discomfort and embarrassment, as the story from research participant 2 reflects:

'I arranged with the mine captains and they gave me their change house [there weren't any for women] $]^{1}$, I had to wait until they finished, then they would give me the key and I could change. And the toilets ....I always had a guy that I asked to watch over me [there were no toilets for women].'

Research participant 4 shares a similar experience:

'Our change house is small and the men's change house is big... you would find that when you get into the change room you don't have a locker, you have to go home with a big bag with gumboots and overalls and everything there.'

1.The authors added the words in square brackets to clarify the sentence construction of the participants in the context of the discussion. They omitted words like 'uhhmm' and 'you know' from the verbatim extracts to improve the flow and ease of reading.
Research participant 4 also related how the existing discriminatory maternity policies affected her. They perpetuated procedural gender inequalities in her work environment:

'You are not allowed to work underground when you are pregnant, $[o r]$ allowed to be on the shaft because women when they [get] pregnant they get paid for [the first] five months [of pregnancy] and the other [remaining] months you just sit at home without getting paid. As soon as you say "I am pregnant" they make [you sign] a form and say go home. They pay you for [the first ] five months [of pregnancy] and the other months [leading up to the birth and after birth] you don't get paid... After birth many women come back [and] when you go and talk to them you find out that they have money problems.'

Spill over of stereotypical gender roles and expectations that relate to women: From the participants' narratives (see the supporting verbatim text and researcher memos in Box $1 \mathrm{a}$ and Box 1b), it was clear that the traditional gender roles and stereotypes of women in society existed in the workplace. The idea of women defying traditional cultural norms and entering gender atypical roles remained a novelty to participants' families as well as colleagues. This resulted in a lack of social, emotional and work support. From the women's experiences, the authors also found that the predominant social constructions about gender roles affect the organisational culture and could underpin biased employment policies and management strategies to

BOX 1a: Verbatim extracts that substantiate spill over and male resistance or prejudice.

Spill over of stereotypical gender roles and expectations as they relate to women

RP5: 'When I told my own grandfather that I was going to study engineering, he was like "is that really work for a woman?".'

RP4: 'You know South African men want you to respect them. If you say something you must say it with respect.'

You must say it with respect.' RP2: 'As a shift boss I battled, because the guys and most of them are the white
South African guys, they believe that you should be in the kitchen pregnant and South African guys, they
you cannot do anything.'

RP2 discovered: '... they believed that if a woman visited a work place, it's bad luck, people are going to die... that there would be fatalities in that section. So had to fight against the culture.'

Memo

Gender-based stereotypical roles permeate the organisational culture. Societal values and norms see men as the dominant, breadwinner figure. The expectation for women is to play a submissive role and follow more domesticated careers.

Superstitions based on cultural beliefs also permeate the workplace, taxing women's ability to gain acceptance.

BOX 1b: Verbatim extracts that substantiate spill over and male resistance or prejudice.

Lack of real transformation because of male resistance and prejudices

RP4: 'Coming to work it was tough because men wanted us to work like them, they won't say that "you are a man I will give you two rails and [you are a woman] I will won't say that "you are a man I will give you

give you one rail ....No, its two [rails] each". RP4: 'Some are stubborn; even if he passes you and sees that you are struggling he'll not help you. They [men] say you said you wanted equality, this is the equality that you wanted.'

RP2: 'They don't share their knowledge, I think they feel threatened ...and they will nail you to get rid of you. Your head of department also doesn't believe in you, so where they can nail you, they nail you, so it's a battle the whole time.' RP2: 'There can nail you, they nail you, so it's a battle the whole time.' RP2: 'There was no assistance for you as a newly appointed mine overseer. There was no practical guidance or someone that [could] look over you.'

Memo

Efforts to show women that there is no place for gender leniency disguise vindictive and punitive attitudes and behaviour towards women.

Male colleagues' sabotaging and unsupportive behaviour deliberately isolate women. 
the disadvantage of women who work in male-dominated occupations.

Lack of real transformation because of male resistance and prejudices: Despite the apparent organisational efforts to accommodate women by employing them, in practice the women in this study experienced little genuine accommodation. Instead, they experienced vindictive and unsupportive behaviour from male colleagues. Of the women in this study, it seemed to affect those in the mining sector predominantly. Box $1 \mathrm{~b}$ quotes them verbatim, alongside the memos the authors made whilst analysing the data.

\section{Women's unique physical, identity and work-life balance needs}

Box 2 briefly presents women's unique needs and supplies verbatim text that supports the authors' interpretations.

Physical and health related difficulties women experience: Labour-intensive work, inadequate physical strength and hormone cycles add to the emotional strain of working in a male-dominated occupation. For example, one cannot ignore women's monthly menstrual cycles because they tax women's bodies with fatigue and body pain. Coupled with no support (RP2: 'there's nothing in place for females to cope'), the authors found that women's unique physical needs have negative effects on the physical and mental wellbeing of the participants.

Negative work-identity perceptions: Overt and subtle practices show a prevailing lack of confidence in women's competence and their exacerbated negative self-perceptions, low self-efficacy and low self-esteem. Although none of the women in the study intended to leave their male-dominated occupations, they demonstrated a reluctance to progress into the more intensely competitive male roles because of these negative self-perceptions. Rather, they opted for those 'softer' roles whilst remaining in male-dominated environments.

Work-life balance: The participants' different roles emerged as a source of conflict because they regularly needed to balance being primary caregivers with being career women. Even without children and being unmarried, participants still emphasised how their prominent role in the household tax their work commitments and vice versa. They felt that their domestic responsibilities inhibited the pace of their career progression compared to their male colleagues. They also acknowledged that career advancement and achieving work-life balance are mutually exclusive. This meant that they had to neglect aspects of one in order to focus on the other.

\section{Elements of resilience for women in male- dominated occupations}

Adjusting well, despite potentially adverse challenges and bias in the male-dominated work environment, was a core focus in the authors' inquiry. Various orientations, attitudes and overt strategies emerged from the participants' narratives. The participants used them in order to allow them to cope, adjust and remain motivated in their maledominated occupations.

\section{Coping strategies and resources}

Elements of resilience that emerged from the data relevant to coping strategies and resources include:

- appreciation of feminine advantage

- adopting male characteristics

- mentorship.

After the discussion, the authors provide a summary of the most relevant verbatim quotes to support their interpretations in Box 3.

Appreciation of feminine advantage: Some participants had noted an appreciation of, and reliance on, their femininity and integrated that into their work identity. Another two criticised the manipulative use of femininity and females' use of sexual prowess in order to gain acceptance. Whether constructive or manipulative, it seems that women rely on their femininity to cope with the challenges of maledominated occupations.

Adopting male characteristics: Participants frequently adopted male characteristics, like foul language and aggressive verbal and non-verbal behaviour, in order to fit into their environments better. One participant also moderated or 'diluted' her feminine appearance in an effort to avoid unwarranted sexual attention or objectification by her male colleagues.

BOX 2: Women's unique physical, identity and work-life balance needs: Verbatim extracts by identified subtheme.

\begin{tabular}{|c|}
\hline \\
\hline $\begin{array}{l}\text { P2 stated: 'I think the stress was too much for me and I started to have problems } \\
\text { ith my female hormones and I had operations... I started menopause at } 42 \text { years } \\
\text { ut we didn't know it, I was feeling very very bad and they did all the tests. They } \\
\text { aid the underground, heat, the environment and the stress levels (were) taking } \\
\text { toll... I think the biggest challenge for the females is you know your monthly } \\
\text { ycles, there's nothing that's in place for females to cope really and it influences } \\
\text { he production site.' } \\
\text { P4: 'I am less tired than underground, you know when I came from underground } \\
\text { used to sleep a lot, when I got home I didn't want [to do] anything I just wanted } \\
\text { sleep....' } \\
\text { P1: 'Being the only project manager before they employed [my boss] I actually } \\
\text { urnt out. My body just said stop, that's it, and I was off work for a long time.' }\end{array}$ \\
\hline Negative work-identity perceptions \\
\hline $\begin{array}{l}\text { loes a presentation and does it well, there is no comment, but if you } \\
\text { tation well they will be like "oh wow, well done" like they were not } \\
\text { to be able to do it.' } \\
\text { In't believe in a female, so I had to work twice as much as a male } \\
\text { em.' } \\
\text { tof look down [on] you and they talk to you like you are an idiot first } \\
\text { k to you like you are a child secondly.' } \\
\text { te biggest problem was my [low self] esteem, the way that I thought } \\
\text { d me and the way that I perceived myself in this position.' } \\
\text { hey seem to look down at you, you know, you can't cope and all... I } \\
\text { couple of years it gets to you and you do eventually break.' }\end{array}$ \\
\hline Work/life bala \\
\hline $\begin{array}{l}\text { RP5: 'We both get home at the same time...at like } 7 \mathrm{pm} \text {, then he can go and sit } \\
\text { on the couch and then I still have to now start slaving away at the stove, washing } \\
\text { dishes and whatever and if I say "please can you do this" he will be like "why am } \\
\text { I supposed to do that?". I had now dedicated Saturday mornings to clean...and } \\
\text { after six months I was like "we are getting a helper or a cleaner", I need some } \\
\text { time to take a chill pill. So I think that worries me more, the dynamics [at home] } \\
\text { worries me more than in the office.' } \\
\text { RP3: 'I may still be able to do what the males do but it may take me longer } \\
\text { because I have got other responsibilities when I get home. You know when I get } \\
\text { home, I cannot focus on [work], I have got other things to focus on. Basically my } \\
\text { time at work is all I have got.' } \\
\text { RP2: 'There are a few females that are really making a difference, but most of } \\
\text { them [are] moving out of the production site the moment they get children } \\
\text { because it's very difficult for you as a mum. I mean I was a single mum at that } \\
\text { time [and] that's the biggest challenge.' }\end{array}$ \\
\hline
\end{tabular}


Mentorship: Participants saw mentorship as a legitimate means of gaining support and guidance in the organisation and of achieving career success. All participants expressed a need for mentoring as a support system to mitigate their often-hostile environments and as an effective coping strategy. They expressed the need for women mentors in particular.

\section{Motivational work aspects}

Elements of resilience that emerged from the data as relevant to motivational work aspects include:

- optimistic career expectations

- work engagement

- successful career experiences.

Optimistic expectation of future career possibilities: A positive outlook on career opportunities, despite having experienced adversity, facilitated coping and perseverance amongst the research participants. Research participant 2 expressed her belief that things would change for the better and that resistance and destructive stereotypes would disappear:

'Let me tell you one thing, there are still a lot of the males that don't accept women but we are working them out. We don't need a person like that because the way that the mines are

\section{BOX 3: Coping strategies: Verbatim extracts by identified subtheme.}

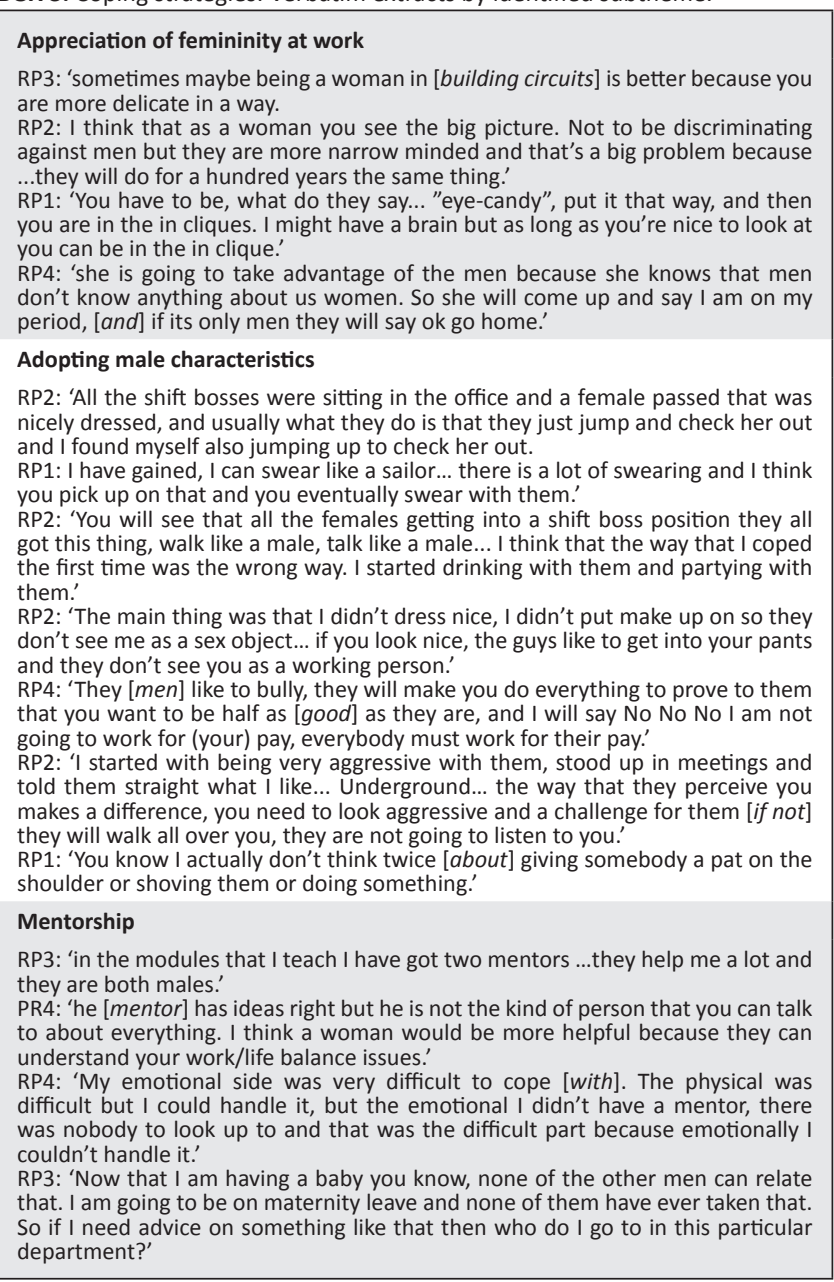

changing and are treating people, there is no space for the old male dominant type of character. So they are changing... slowly, but they are. There is a lot of resistance still but you can see the whole mining environment is changing.'

The participants' positive attitudes towards their male counterparts and their acknowledgement of male colleagues' efforts to support the acceptance and integration of female colleagues also reflected optimism. Research participant 3 noted:

'As a woman, they (male colleagues) encourage you more ... because it's such a minority you don't find many women doing research. They encourage you to do it and so I do have the opportunity.'

Challenging work and work engagement: The authors thought that the data provided evidence that the women had grown to enjoy the nature of their jobs and had become accustomed to them. All the participants shared experiences that illustrated the pleasure and engagement they derived from their jobs. Research participant 5, for example, stated:

'I really had fun when I was out in the field. There is a time that they gave me this project to put meters at some stations of ours and every chance I would get when the guys tell me they are going to a certain substation to do the installations, I would be like just tell me the date that you are going ... I am going to come.'

Even those who initially disliked their environments started to embrace them, making them part of their identities. As Research participant 4 reflected:

'It's nice [working] underground you know, if you don't know it you can't see what I am saying, but if you stay there for a long time like two years you will see that underground is a nice place to be... I am actually so comfortable and I really like what I am doing now.'

The authors found a common thread amongst the participants: that they thrived on the challenges thrown at them and derived pleasure from overcoming the odds against them:

'I believe in women and the challenge that they gave me [when they told] me that women won't make it. I like a challenge, so I think that's the main thing... I was a very active type of person driving trucks and forklifts and things like that, I love the challenge.' (RP2)

'...more often than not when they have had female learners they refused to climb, but I was like 'hey bring it on' when else am I going to get a chance to climb on a transformer.' (RP5)

'It's hard to do both [jobs] at the same time because at the end of the day the mine captain will want you to do his job, the job that you are paid to do and the one as a safety representative you do not get paid. You have to do both [jobs], it was hard but I loved it.' (RP4)

Recognition and success: The authors found significant career success experiences in the data that motivated these women to remain in their male-dominated occupations. The successes that women could refer to were sources of inspiration and assured them that it was worth their while to remain in these occupations. Some of the women had made monumental strides and pioneered the way for other females who came after them. One such example was research participant 2, the first woman allowed to work underground for her company: 
'In 1998 when the legislation changed and females could go underground, the general manager said that nobody will allow women underground. I challenged them and asked them if they will give me a trial and then we could decide if a woman could make it or not. So for six months I had to do all the underground occupations like the drilling, the timber and everything and it was tough for me... and then after six months every underground job that I did, they signed me off and usually the general manager came and visited me and see if I can drill, can put timber in etc. It was a big issue for [the company] to see if a woman can be successful and then after six months they offered me a learner official job.'

Other career successes included recognition from male colleagues who even nominated a woman as their safety representative, a position of authority: 'they listened and they would come to me and say "how can we do this etc"' (RP4). Career success experiences did not have to be big or even formally acknowledged by male colleagues or the organisation to be valuable to the women. Some of the successes were small and more subtle, as research participant 5 experienced when she won over a difficult client:

'I found the more they [client] had a chance to deal with me directly the more they realised and understood that "ok she is actually here for a reason, she does know what she is talking about and she is not just someone's right hand person".'

Similarly, research participant 1 noted: 'When you start talking back, they sort of step back and think wait maybe she actually knows what she's talking about'. Others also received affirmation of their success from colleagues, as research participant 2 experienced:

'A lot of the males, with a lot of the women coming in, will come back to me and say "you know what, you were great man, that time you [worked in production] you were great".'

\section{Discussion}

The authors' main objective was to explore the experiences of women who worked in male-dominated occupations and to develop a conceptual understanding of the unique challenges they face and of the resources that facilitated their career resilience and perseverance.

Their proposed conceptual understanding reveals the participants' unique challenges as women who worked in male-dominated occupations, as well as elements of their resilience. Formal and covert gender-discriminatory and biased organisational practices, as well as their unique physical, identity and work-life balance needs, were the main challenges the women in this study experienced. Their resilience is evident in their use of creative coping strategies and resources and in the motivational work aspects that enabled them to persevere in pursuing career success.

Discrimination and bias seem to be the predominant challenges women face, whether they are evident in formal policies and tangible resources or in covert aspects of the organisational culture that reflect debilitating stereotypes and male resistance. Previous studies also show that women in general experience both overt and subtle mistreatment that inhibits their career progression in male-dominated fields (Harris \& Giuffre, 2010; Sargent, 2005; Ward, 2004; Watts, 2009).

The authors' findings echo the findings of Madikizela and Haupt (2009), who reported a lack of written gender policies and of gender-based education material in the construction industry. The authors agree with them that a lack of visible and tangible commitment to empowering women in organisations remains, despite employment equity legislation.

Covert discriminatory behaviour manifests in stereotypical male-female gender roles and expectations that permeate the work place. It also manifests in male colleagues' resistance to accommodate and support female employees. Stereotypes and male resistance emanate from cultural and societal norms because of patriarchal structures in family units, where women play submissive roles to men (cf. Bobbit-Zeher, 2011; Mathur-Helm, 2006; Cha, 2013).

These stereotypical gender roles and expectations spill over into organisations' structures and behavioural dynamics, thereby sustaining biased and discriminatory work role allocations as well as unwillingness on the part of men to relinquish the masculine culture in order to incorporate female colleagues. Women still have to contend with the time efficiency problem of fulfilling their age-old stereotypical obligations as homemakers and their obligations as paid workers (Cha, 2013; Franks et al., 2006). Consequently, the authors found that the organisational culture in maledominated occupations continues to reflect an underlying patriarchal role distribution to the detriment of female equality in male-dominated occupations (see also Chisholm, 2001; Chovwen, 2007; Hicks, 2012).

Occupation-specific studies have reported similar findings. Davey and Davidson (2000) found that the low prominence of female pilots in their profession leads to sexist jokes, derogatory comments about women, and, on occasion, aggressive and sexist behaviour from male colleagues and even passengers. Mathur-Helm (2005) ascribed management strategies, in which organisations treat women in biased ways, to the social constructs, attitudes, norms, values and stereotypes evident in corporate culture.

The study of Dodge, Valcore, and Gomez's (2011) into female police officers in male-dominated special weapons and tactical teams (SWAT) supports this. They asserted that the challenge of integrating women officers into the SWAT subculture required changing perceptions in an overall culture that continued to endorse the values of masculinity.

In the same vein, Penceliah (2011) affirms that, in South Africa, transformation can happen only when both men and women have equal participation in all facets of society. Interestingly, the study of Bobbitt-Zeher (2011) found that gender discrimination and stereotyping occurs in all 
occupations, irrespective of their gender distribution ratios. This implies that women uphold gender stereotypes as much as men do. Franks et al. (2006) noted that women and men continue to perform their traditional roles - women carry on in their nurturing roles and men in the roles of breadwinners. The fact that women maintain these stereotypical beliefs, whilst building careers, places a burden on them (see Franks et al., 2006).

Women's unique physical, identity and work-life balance needs exacerbate their experiences of facing challenges in male-dominated occupations. The authors found that maledominant work settings do not accommodate or empower women.

The demanding nature of labour intensive work - along with working in perpetually gender-hostile environments triggers physical and mental stress. A study by Innstrand, Langballe, Falkum, and Aasland (2011) found that women, in general, reported more emotional fatigue and physical exhaustion than men did across eight different occupational groups.

In this study, women seemed to have assimilated negative perceptions about their competence. This resulted in a lack of self-confidence and self-efficacy. Retaining their confidence and self-efficacy seemed to be a consistent challenge for the participants because many male colleagues continued to undermine women's capabilities with perceptions of female incompetence.

To support this, Michie and Nelson (2006) found that women showed less self-efficacy in the male-dominated IT field, coupled with men having less positive attitudes towards the capabilities of women in IT. Urban (2010) also noted a lower entrepreneurial self-efficacy in women.

The authors found work-life balance issues to be fundamental in the lives of the female participants, specifically in the conflicting demands of work-home roles that tax women's ability to cope at home and at work. Likewise, Chovwen's (2007) study revealed that women stated that work-family conflict, amongst other things, was a major inhibitor of career progress in executive male-dominated environments in Nigeria. Cha (2013) further emphasises that increased work responsibilities do not tax men's family obligations as much as they do women's because women retain the bulk of the household responsibilities. This makes them prone to role overload (see also Franks et al., 2006; Harris \& Giuffre, 2010; Mostert, 2009).

Interestingly, in this study, women who are married or have children are not the only ones who experience role conflict. Single women without children also felt overwhelmed by the culturally prescribed duties they have to carry out at home. Even career-orientated women must still do most of the cooking, shopping, housework and childcare. This causes role overload and conflict (Finnemore \& Cunningham,
1995; Mostert, 2009). Harris and Giuffre (2010) regard the work-family conflict burden as heavier for women in maledominated occupations because the male perspective of complete devotion to work dominates the male-dominated organisational culture.

Despite the challenges rampant in male-dominated occupations, the authors found that the women in this study displayed elements of resilience that empowered them to achieve satisfaction and tenure in their occupations. Despite having few to no formal coping resources, women seemed to adjust and devise their own. Some of these strategies come at personal cost. For example, Harris and Giuffre (2010) and Watts (2009) found that male-dominated work perspectives might cause women to decide to delay or forego childbearing in order to remain in their occupations. Furthermore, Mathur-Helm (2006) reports that women will even decline career opportunities.

In this study, there is an apparent contradiction: women drift between two opposing behaviours. They use their femininity and adopt male characteristics, with the latter being more common. According to Davey (2008), women seem caught between resisting the patriarchal process by retaining their femininity and engaging in masculine tactics. This opens them to accusations of selling out and engaging in activities they condemn.

The findings of this study also highlighted mentoring as a vital and constructive coping strategy for women in maledominated occupations. This is similar to the high premium women in the Ghanaian accounting field placed on mentors (Hinson, Otieku \& Amidu, 2006). The current study found a consensus amongst the women: that mentoring functions should be all encompassing, provide guidance and support in work matters and attend to their emotional and worklife balance concerns. The availability of female mentors in certain positions and occupations seems to be an issue in male-dominated environments (Chovwen, 2004). The participants in this study particularly expressed the need for female mentors.

The authors' participants found several aspects of their work that motivated them. They empowered the women to remain in male-dominated occupations despite the highly challenging conditions. Some of the women had optimistic expectations of women's future career possibilities and remained positive about the progressive transformations towards equalising women in historically male-dominated occupations. The study of Madikizela and Haupt (2009) of women in the construction industry reported similar sentiments.

It seems to the authors that overcoming the unique difficulties that they find in male-dominated occupations positively challenge the women, who remain in these occupations, to overcome the unique difficulties they find there. For them, it results in feelings of engagement and 
experiences of recognition and success. They seem to take pride in overcoming gender challenges at work. This shows a personal drive for achievement and success.

Paradoxically, the minority status that make women targets for discrimination and bias also makes them stand out as distinctive and pioneering, aspects that Bagihole (2006) identified as constructive to the work identity of female priests.

The participants in this study recognised that achieving any level of success and recognition as indicators of their potential and as reassurances of their decision to remain in their male-dominated occupations.

Sturges (1999) found that women are less inclined than men are to define career success in terms of hierarchical and financial progression because they construct success on a range of internal and intangible criteria like achievement, accomplishment, personal recognition and influence. Strategies that aim to develop women's careers are likely to fail unless organisations attempt to understand more clearly how women actually perceive their own career success (Sturges, 1999).

\section{Limitations of the study}

The occupations the participants represented are only a small fraction of the male-dominated occupations that exist. However, the participants were rich in information about the phenomenon under study. English was the language medium the authors used whilst collecting data. This may have affected the ability of subjects, whose home language was not English, to express themselves as freely and eloquently as they may have done had they been using their mother tongue.

\section{Recommendations}

Organisations that need to attract women into maledominated occupations and to retain their services should not take for granted that these women will successfully assimilate in these environments. Organisations need to introduce formal organisational initiatives to create an environment conducive for women entering and remaining in male-dominated occupations.

The nature of the organisational initiatives should include strong, visible and effective policies geared towards accommodating women's physical needs, change management strategies and practices to create femaleintegrated cultures and to provide appropriate emotional support and mentorship.

A review of current policies aimed at women, like maternity leave, is required along with the development of more effective strategies for pregnant women who cannot work in hazardous environments. Organisations should begin to improve gender policies, in consultation with the women concerned, and should include gender-sensitivity training in all employees' induction and orientation programmes.

In order to get a more comprehensive picture of the experiences of women in male-dominated occupations, future studies should include women who have worked in male-dominated occupations but who have subsequently left for more gender-neutral or female-dominated environments. Having noticed specific cultural traditions and gender role stereotypes from the participants' narratives, the authors suggest that future research should also investigate how different cultures affect the integration of women in maledominated occupations.

\section{Conclusion}

The authors conclude that women in male-dominated occupations often work in conditions that do not cater for their unique needs because of covert and entrenched gender-biased organisational cultures. Very few supportive organisational practices are at the disposal of these women and organisations often leave them to their own devices when it comes to coping in their respective male-dominated occupations.

Nevertheless, organisations can motivate women to remain in male-dominated work settings if they provide the women with tangible physical support and female-focused policies, visible career opportunities, challenges to entice their personal drive for achievement and different ways of recognising their success. Gender balanced mentorship is vital for assisting these women to cope and persevere.

\section{Acknowledgements Competing interests}

The authors declare that they have no financial or personal relationship(s) that may have inappropriately influenced them when they wrote this article.

\section{Authors' contributions}

P.M. (University of South Africa) collected and transcribed the data, conducted the literature review and interpreted the findings as part of her Master's dissertation. A.B. (University of South Africa) supervised the research design and assisted in integrating the literature with the findings and with the reworking of the Master's dissertation into article format.

\section{References}

Anonymous. (2012). Weaknesses in South Africa's progress with women's equality in the Millenium development goals. Agenda: Empowering women for gender equity, 26(1), 91-103.

Akingbade, R.E. (2010). Between a rock and a hard place. Backlash towards agentic women aspiring to high ranking jobs in Nigeria. Gender and Behaviour, 8(2), 3265-3278

Ashraf, M. (2007). Factors affecting female employment in male-dominated occupations: evidence from the 1990 and 2000 census data. Contemporary Economic Policy, 25(1), 119-130. http://dx.doi.org/10.1111/j.14657287.2006.00022.x

Babbie, E., \& Mouton, J. (2001). The Practice of Social Research. Cape Town: Oxford University Press. PMid:11247957 
Bagilhole, B. (2006). Not a glass ceiling more a lead roof. Experiences of pioneer women priests in the Church of England. Equal Opportunities International, 25(2), 109-125. http://dx.doi.org/10.1108/02610150610679538

Bobbitt-Zeher, D. (2011). Gender discrimination at work: connecting gender stereotypes, institutional policies and gender composition of the workplace. Gender \& Society, 25(6), 764-786. http://dx.doi.org/10.1177/0891243211424741

Bowen, P., Cattell, K., \& Distiller, G. (2008). South African quantity surveyors: issues of gender and race in the workplace. Acta Structilia, 15(1), 1-21.

Brink, B., \& de la Rey, C. (2001). Work-family interaction strain: coping strategies used by successful women in the public, corporate and self-employed sectors of the economy. South African Journal of Psychology, 31(4), 55-61.

Cha, Y. (2013). Overwork and the persistence of gender segregation in occupations. Gender \& Society, 27. Retrieved January 31, 2013, from PsycARTICLES database. http://dx.doi.org/10.1177/0891243212470510

Charmaz, K. (2011). A constructivist grounded theory analysis of losing and regaining a valued self. In F.J. Wertz, K. Charmaz, L.M. McMullen, R. Josselson, R. Anderson
$\&$ E. McSpadden (Eds.), Five ways of doing qualitative analysis, (pp. 165-204). $\&$ E. McSpadden (Eds.),
New York: Guilford Press.

Chisholm, L. (2001). Gender and leadership in South African educational administration. Gender and Education, 13(3), 87-399.

Chovwen, C.O. (2004). Mentoring and women's perceived professional growth. IFE Psychologia: An International Journal of Psychology in Africa, 12(1), 126-132.

Chovwen, C.O. (2007). Barriers to acceptance, satisfaction and career growth Implications for career development and retention of women in selected male occupations in Nigeria. Women in Management Review, 22(1), 68-78. http:// dx.doi.org/10.1108/09649420710726238

Cooney, A. (2011). Rigour and grounded theory. Nurse Researcher, 18(4), 17-22. PMid:21853888

Damaske, S. (2011). A 'major career woman?' How women develop early expectations about work. Gender and Society, 25(4), 409-430. http://dx.doi. org/10.1177/0891243211412050

Crotty, M. (2005). The foundations of social research: Meaning and perspective in the research process. London: Sage.

Danziger, N., \& Eden, Y. (2007). Gender-related differences in the occupationa aspirations and career-style preferences of accounting students. A cross-sectional comparison between academic school years. Career Development International, 12(2), 129-149. http://dx.doi.org/10.1108/13620430710733622

Davey, C.L., \& Davidson, M.J. (2000). The right of passage? The experiences of female pilots in commercial aviation. Feminism \& Psychology, 10(2), 195-225.

Davey, K.M. (2008). Women's accounts of organisational politics as a gendering process. Gender, Work and Organisation, 15(6), 650-671. http://dx.doi. org/10.1177/0959353500010002002

Dodge, M., Valcore, L., \& Gomez, F. (2011). Women on SWAT teams: separate but equal? Policing: An International Journal of Police Strategies \& Management, 34(4), 699-712. http://dx.doi.org/10.1108/13639511111180298

Du Plessis, Y., \& Barkhuizen, N. (2012). Career path barriers experienced by women engineers. Paper presented at the 12th European Academy of Management Conference, Rotterdam, Netherlands. Retrieved January 14, 2013 from http:// www.optentia.co.za/publications.php

England, P. (2010). The gender revolution. Gender \& Society, 24(2), 149-166. http:// dx.doi.org/10.1177/0891243210361475

Feyerherm, A., \& Vick, Y.H. (2005). Generation X women in high technology. Overcoming gender and generational challenges to succeed in the corporate environment. Career Development International, 10(3), 216-227. http://dx.doi. org/10.1108/13620430510598337

Finnemore, M., \& Cunningham, P. (1995). Women and the workplace. In A. van der Merwe (Eds.), Industrial Sociology: A South African Perspective, (pp. 177-210). Isando: Lexicon Publishers.

Franks, K., Schurink, W., \& Fourie, L. (2006). Exploring the social construction of life roles of career-oriented women. South African Journal of Industrial Psychology, 32(1), 17-24.

Frome, P.M., Alfeld, C.J., Eccles, J.S., \& Barber, B.L. (2006). Why don't they want a male dominated job? An investigation of young women who changed their occupational aspirations. Educational Research and Evaluation, 12(4), 359-372. http://dx.doi.org/10.1080/13803610600765786

Glaser, B. \& Strauss, A. (1967). The discovery of grounded theory. Chicago: Aldine. PMCid:224645

Gordon-Finlayson, A. (2010). QM2: Grounded Theory. In M. Forrester (Ed.), Doing Qualitative Research in Psychology, (pp. 154-176). Thousand Oaks: SAGE.

Harris, D.A., \& Guiffre, P. (2010). The Price you pay : How female professional chefs negotiate work and family. Gender Issues, 27, 27-52. Published online 12 May 2010. http://dx.doi.org/10.1007/s12147-010-9086-8

Hartmann, H. (2010). Capitalism, patriarchy and job segregation by sex. In J. Goodman (Ed), Global perspectives on gender and work: Readings and interpretations, (pp. 54-62). Plymouth: Rowman \& Littlefield Publishers Inc. PMid:20189258
Hicks, J. (2012). Opinion piece: gender transformation in the workplace. Commission for Gender Equality. Downloaded from www.cge.org.za on 6 February 2013.

Hinson, R., Otieku, J., \& Amidu, M. (2006). An exploratory study of women in Ghana's accountancy profession. Gender and Behaviour, 1(4), 589-609.

Innstrand, S.T., Langballe, E.M., Falkum, E., \& Aasland, O.G. (2011). Exploring withinand between-gender differences in burnout: 8 different occupation groups. International Archives of Occupational and Environmental Health, 84(7), 813-824. http://dx.doi.org/10.1007/s00420-011-0667-y, PMid:21688002

Lewis-Enright, K., Crafford, A., \& Crous, F. (2009). Towards a workplace conducive to the career advancement of women. South African Journal of Industrial Psychology, 35(1), 9 pages. $h$ ttp://dx.doi.org/10.4102/sajip.v35i1.832

Llyod, H.R., \& Mey, M.R. (2007). Gender differences in perceptions of workplace progression: an automotive industry case study. Southern African Business Review, 11(3), 102-108.

Madikizela, K., \& Haupt, T. (2009). Why do South African women choose careers in construction? Acta Structilia, 16(2), 46-68.

Mathur-Helm, B. (2005). Equal opportunity and affirmative action for South African women: a benefit or barrier? Women in Management Review, 20(1), 56-71. http://dx.doi.org/10.1108/09649420510579577

Mathur-Helm, B. (2006). Women and the glass ceiling in South African banks: an illusion or reality? Women in Management Review, 21(4), 311-326. http://dx.doi. org/10.1108/09649420610667028

Michie, S., \& Nelson, D.L. (2006). Barriers women face in information technology careers. Self-efficacy, passion and gender biases. Women in Management Review, 21(1), 10-27. http://dx.doi.org/10.1108/09649420610643385

Moorosi, P. (2007). Creating linkages between private and public: challenges facing woman principles in South Africa. South African Journal of Education, 27(3), 207-521.

Mostert, K. (2009). The balance between work and home: The relationship between work and home demands and ill health of employed females. South African Journal of Industrial Psychology, 35(1), Art.\#743, 8 pages. http://dx.doi.org/sajip. Journal of

Penceliah, Y. (2011). Gender mainstreaming with special reference to senior management in local government. Journal of Public Administration, 46(1), 868880 .

Raghuram, P. (2008). Migrant women in male-dominated sectors of the labour market: a research agenda. Population, Space and Place, 14, 43-57. http://dx.doi. market: a research agenc

Prescott, J., \& Bogg, J. (2011). Career attitudes of men and women working in the computer games industry. Eludamos, 5(1), 7-28.

Sargent, P. (2005). The gendering of men in early childhood education. Sex Roles, 52(3-4), 251-259. http://dx.doi.org/10.1007/s11199-005-1300-x

Shantz, A., \& Wright, K. (2011). Networking with boundary spanners: a quasi-case study on why women are less likely to be offered an engineering role. Equality Diversity and Inclusion: An International Journal, 30(3), 217-232. http://dx.doi. org/10.1108/02610151111124950

Snape, D. \& Spencer, L. (2004). The foundations of qualitative research. In J. Ritchie \& J. Lewis (Eds.), Qualitative research practice: A guide for social science students and researchers, (pp. 1-23). London: Sage.

Strauss, A., \& Corbin, J. (1990). Basics of qualitative research: Grounded theory procedures and techniques. California: Sage Publications Inc.

Sturges, J. (1999). What it means to succeed: Personal conceptions of caree success held by female and male managers at different ages. British Journal of Management, 10, 239-252.

Taylor, V. (1997). Economic gender injustice: The macro picture. Agenda, 33, 9-24. http://dx.doi.org/10.2307/4066128

Terre Blanche, M., \& Kelly, K. (1999). Interpretive Methods. In M. Terre Blanche \& K. Durrheim (Eds.), Research in Practice, (pp. 123-146). Cape Town: UCT Press.

Urban, B. (2010). A gender perspective on career preferences and entrepreneurial self-efficacy. South African Journal of Human Resource Management, 8(1), 1-8.

Van Aarde, A., \& Mostert, K. (2008). Work-home interaction of working females: What is the role of job and home characteristics? South African Journal of Industrial Psychology, 34(3), 1-10.

Van den Berg, H.S., \& Van Zyl, E.S. (2008). A cross-cultural comparison of the stress experienced by high-level career women. South African Journal of Industrial Psychology, 34(3), 17-21.

Ward, J. (2004). Not all differences are created equal: multiple jeopardy in a gendered organisation. Gender \& Society, 18(1), 82-102. http://dx.doi. org/10.1177/0891243203259503

Watts, J.H. (2009). 'Allowed into a man's world' meanings of work-life balance: Perspectives of women civil engineers as 'minority' workers in construction. Gender, Work and Organisation, 16(1), 37-57. http://dx.doi.org/10.1111/j.14680432.2007.00352.x 